\title{
Association between HIF1A rs11549465 polymorphism and risk of prostate cancer: a meta-analysis
}

\author{
Xiao-Dong Li ${ }^{1, *}$, Hao $\mathbf{Z i}^{1, *}$, Cheng Fang ${ }^{2}$ and Xian-Tao Zeng ${ }^{1,2,3}$ \\ ${ }^{1}$ Department of Urology, Center for Evidence-Based Medicine, Management Office of Scientific Research and Postgraduate \\ Affairs, Huaihe Hospital of Henan University, Kaifeng, China \\ ${ }^{2}$ Center for Evidence-Based and Translational Medicine, Zhongnan Hospital of Wuhan University, Wuhan, China \\ ${ }^{3}$ Department of Urology, Zhongnan Hospital of Wuhan University, Wuhan, China \\ * These authors are the co-first author \\ Correspondence to: Xian-Tao Zeng, email: zengxiantao1128@gmail.com
}

Keywords: HIFIA, prostate cancer, polymorphism, risk, susceptibility

Received: January 06, $2017 \quad$ Accepted: March 13, 2017

Published: March 22, 2017

Copyright: Li et al. This is an open-access article distributed under the terms of the Creative Commons Attribution License 3.0 (CC BY 3.0), which permits unrestricted use, distribution, and reproduction in any medium, provided the original author and source are credited.

\section{ABSTRACT}

The hypoxia inducible factor 1-alpha (HIF1A) gene has been suggested to play a critical role in cancer progression, and the relationship between HIF1A rs11549465 polymorphism and risk of prostate cancer has been investigated in previous studies. Nevertheless, conflicting results have been obtained. Hence, we reevaluated this issue by means of this meta-analysis, with the purpose of providing more precise conclusion on this issue. The electronic databases of PubMed, EMBASE and Chinese National Knowledge Infrastructure (CNKI) as well as other sources were searched for relevant reports concerning on the role of HIF1A rs11549465 polymorphism in the occurrence of prostate cancer. The strength of the relationship was determined by calculating odds ratios (ORs) with corresponding $95 \%$ confidence intervals (95\% CIs). Besides, subgroup analyses by ethnicity and source of control were further performed to examine this relationship. All statistical analyses were performed using STATA software 12.0. Although HIF1A rs11549465 polymorphism showed a tendency of increasing the risk of prostate cancer, no statistical significance was detected under any genetic models. Similar results were also revealed in subgroup analyses on the basis of ethnicity and control source. Our findings indicate that HIF1A rs11549465 polymorphism may not independently play a significant role in the occurrence of prostate cancer.

\section{INTRODUCTION}

Prostate cancer is the second most common cancer in men all over the world and the fourth most frequent cancer overall, accounting for $11 \%$ of male cancers and $9 \%$ of cancer-related mortality [1-2]. The five-year survival rate is nearly $100 \%$ in patients with localized prostate cancer, but it's only $31 \%$ in those with distant metastases [3]. In the United States, prostate cancer led to 186,000 new cases and 28,600 deaths in 2008 [4]. The pathogenesis of prostate cancer is still not exactly known yet, but inheritance has been suggested to be the clearest one [5]. The risk of developing this cancer is two-fold higher among men having first-degree family members with prostate cancer than those without a family history of the cancer [6]. Some external factors, such as alcohol consumption, chronic inflammation, sexual behavior patterns, and exposure to ultraviolet light, have been put forward to be possibly correlated with the occurrence of the malignancy [7]. In addition, angiogenesis has also been demonstrated to play an important role in prostate carcinogenesis [8-9].

Angiogenesis, referring to the formation of new blood cells from pre-existing cells [10-11], plays an essential role in tumor development and metastasis, which has been indicated to exert negative effects on the disease status and prognosis of various tumors, including urological malignancies [12-13]. Several studies have 
shown that genetic polymorphisms in genes implicated in prostate angiogenesis may affect prostate cancer susceptibility [14-16]. The hypoxia inducible factor-1 (HIF-1) is composed of $\alpha$ and $\beta$ subunits which serves to regulate the cellular response to hypoxia [17-18]. Besides, HIF-1 can also affect the expression of genes such as nitric oxide synthase 2 (NOS2), vascular endothelial growth factor, and erythropoietin (Epo) that are implicated in glucose metabolism, cell survival, iron metabolism, cell proliferation, cell survival, and angiogenesis [18-21]. Since the transcriptional activity of HIF-1 can be affected by the oxygen-regulated expression of HIF1A subunit [22], and the overexpression of HIF1A has been observed in many tumors, HIF1A has been suggested to impact the cancer onset [12, 18, 23]. A polymorphism rs11549465 in $H I F 1 A$ gene has been proposed to be correlated with the occurrence risk of prostate cancer in several studies, but no definitive conclusion on the role of the single nucleotide polymorphism (SNP) in prostate cancer development has been drawn.

In the present study, we incorporated previously published studies to more systematically explore the impact of HIF $1 A$ rs 11549465 polymorphism on prostate cancer risk.

\section{RESULTS}

\section{Study characteristics}

The selection process of eligible studies is presented in Figure 1. Initially, a total of 83 studies were obtained through publication search in electronic databases, and
24 articles were identified from other sources. However, 76 publications were deleted for obvious irrelevance. Among the remaining reports, 24 more were removed for basic research $(n=6)$, not involving HIF $1 A$ rs 11549465 polymorphism $(n=13)$, and no controls $(n=5)$. As a consequence, a total of 4,570 cases and 4,820 controls were included in the present study [14, 24-29]. Table 1 describes principal characteristics of these included studies.

\section{Meta-analysis results}

The relationship between HIF1A rs11549465 polymorphism and susceptibility to prostate cancer is illustrated in Table 2. Overall, in accordance with odds ratios (ORs) and 95\% confidence intervals (95\% CIs), no significant impact of the SNP on prostate cancer was detected under any of the five genetic contrasts TT vs. CC, $\mathrm{TT}+\mathrm{CT}$ vs. $\mathrm{CC}, \mathrm{TT}$ vs. $\mathrm{CC}+\mathrm{CT}, \mathrm{T}$ vs. $\mathrm{C}$, and $\mathrm{CT}$ vs. CC $[\mathrm{OR}=1.17,95 \% \mathrm{CI}=0.61-2.23$ (Figure 2$) ; \mathrm{OR}=1.23$, $95 \% \mathrm{CI}=0.93-1.64 ; \mathrm{OR}=1.15,95 \% \mathrm{CI}=0.61-2.16$; $\mathrm{OR}=1.23,95 \% \mathrm{CI}=0.95-1.60 ; \mathrm{OR}=1.21,95 \% \mathrm{CI}=$ 0.90-1.61]. A similar phenomenon was also revealed after subgroup analyses by ethnicity and control source.

\section{Heterogeneity test}

According to $P$ values of the Chi-Square-based Q-statistical test, significant heterogeneity was observed in total analysis under all those genetic comparisons, so the random-effects model was adopted for OR evaluation. Since subgroup analyses by ethnicity and control

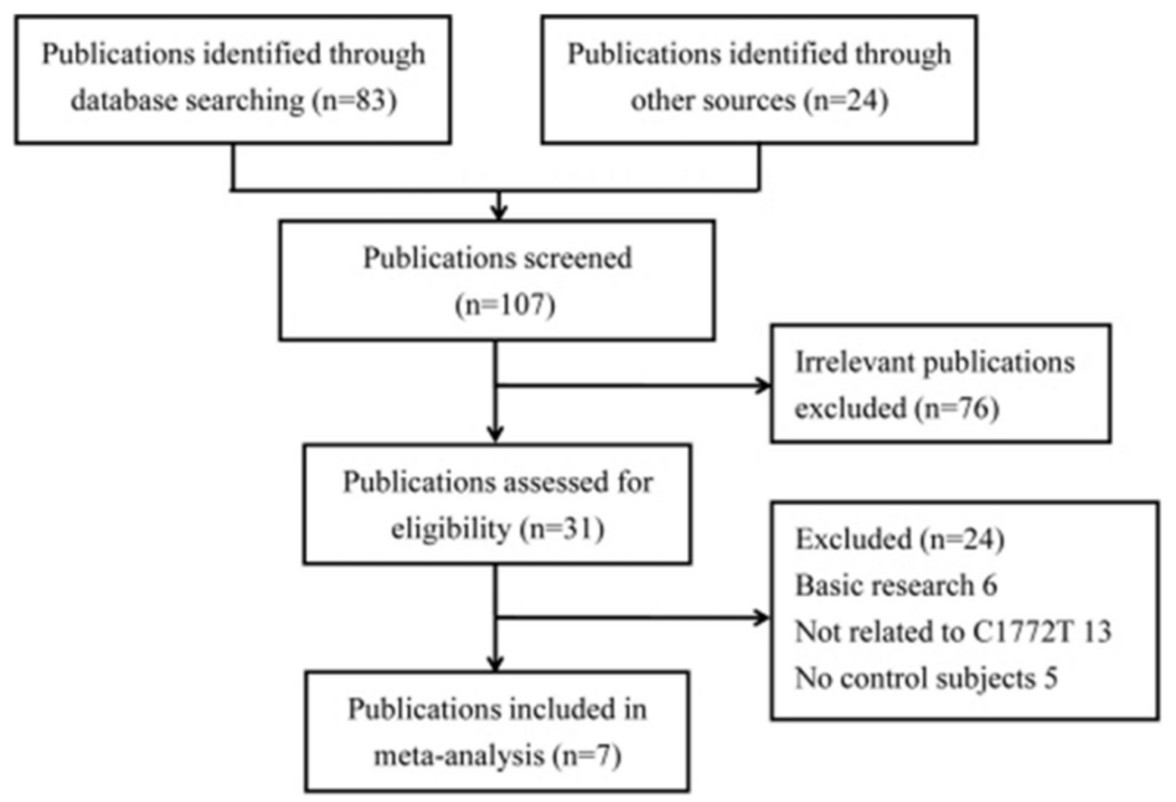

Figure 1: Flow diagram of selecting eligible studies for the meta-analysis. 
Table 1: Major characteristics of all studies included in the present study.

\begin{tabular}{|c|c|c|c|c|c|c|c|c|c|c|c|c|c|c|c|c|}
\hline \multirow{2}{*}{$\begin{array}{c}\text { First author, } \\
\text { year }\end{array}$} & \multirow{2}{*}{ Country } & \multirow{2}{*}{ Ethnicity } & \multirow{2}{*}{$\begin{array}{l}\text { Control } \\
\text { source }\end{array}$} & \multirow{2}{*}{$\begin{array}{l}\text { Sample size } \\
\text { Case/control }\end{array}$} & \multicolumn{5}{|c|}{ Case } & \multicolumn{5}{|c|}{ Control } & \multirow{2}{*}{ HWE } & \multirow{2}{*}{$\begin{array}{c}\text { Genotyping } \\
\text { method }\end{array}$} \\
\hline & & & & & $\mathrm{CC}$ & $\mathrm{CT}$ & $\mathrm{TT}$ & $\mathrm{C}$ & $\mathrm{T}$ & $\mathrm{CC}$ & CT & TT & $\mathrm{C}$ & $\mathrm{T}$ & & \\
\hline $\mathrm{Li}, 2007$ & USA & Caucasian & PB & $1041 / 1234$ & 818 & 209 & 14 & 1845 & 237 & 995 & 221 & 18 & 2211 & 257 & 0.159 & PCR-RFLP \\
\hline $\begin{array}{c}\text { Orr-Urtreger, } \\
2007\end{array}$ & Israel & Caucasian & PB & $251 / 200$ & 170 & 72 & 9 & 412 & 90 & 147 & 51 & 2 & 345 & 55 & 0.288 & PCR-RFLP \\
\hline $\begin{array}{c}\text { Orr-Urtreger, } \\
2007\end{array}$ & Israel & Caucasian & PB & $151 / 100$ & 117 & 27 & 7 & 261 & 41 & 70 & 29 & 1 & 169 & 31 & 0.284 & PCR-RFLP \\
\hline Jacobs, 2008 & USA & Caucasian & $\mathrm{PB}$ & $1420 / 1450$ & 1156 & 252 & 12 & 2564 & 276 & 1138 & 284 & 28 & 2560 & 340 & 0.041 & MassARRAY \\
\hline Foley, 2009 & Ireland & Caucasian & PB & $95 / 188$ & 65 & 30 & 0 & 160 & 30 & 175 & 13 & 0 & 363 & 13 & 0.623 & Sequencing \\
\hline $\mathrm{Li}, 2012$ & China & Asian & $\mathrm{HB}$ & $662 / 716$ & 612 & 48 & 2 & 1272 & 52 & 659 & 57 & 0 & 1375 & 57 & 0.267 & TaqManSNP \\
\hline Fraga, 2014 & Portugal & Caucasian & HB & $754 / 736$ & 579 & 164 & 11 & 1322 & 186 & 566 & 156 & 14 & 1288 & 184 & 0.399 & TaqManSNP \\
\hline Chau, 2005 & USA & Mixed & $\mathrm{PB}$ & $196 / 196$ & 161 & 29 & 6 & 351 & 41 & 179 & 14 & 3 & 372 & 20 & 0.0002 & Sequencing \\
\hline
\end{tabular}

PB, Population-based; HB, Hospital-based; HWE, Hardy-Weinberg Equilibrium; PCR-RFLP, Polymerase chain reaction-restriction fragment length polymorphism.

source partially or totally eliminated the heterogeneity significance, we hypothesized that these two aspects might be able to explain a part of the sources of the heterogeneity.

\section{Sensitivity analysis}

The sensitivity analysis was carried out through recalculating the pooled ORs after individual data-sets were removed one at a time, aiming to examine the influence of each single study on summarized results. Negligible changes in the final results confirmed the reliability of our results.

\section{Publication bias}

Publication bias across the selected studies was assessed with Begg's funnel plot and Egger's test. The

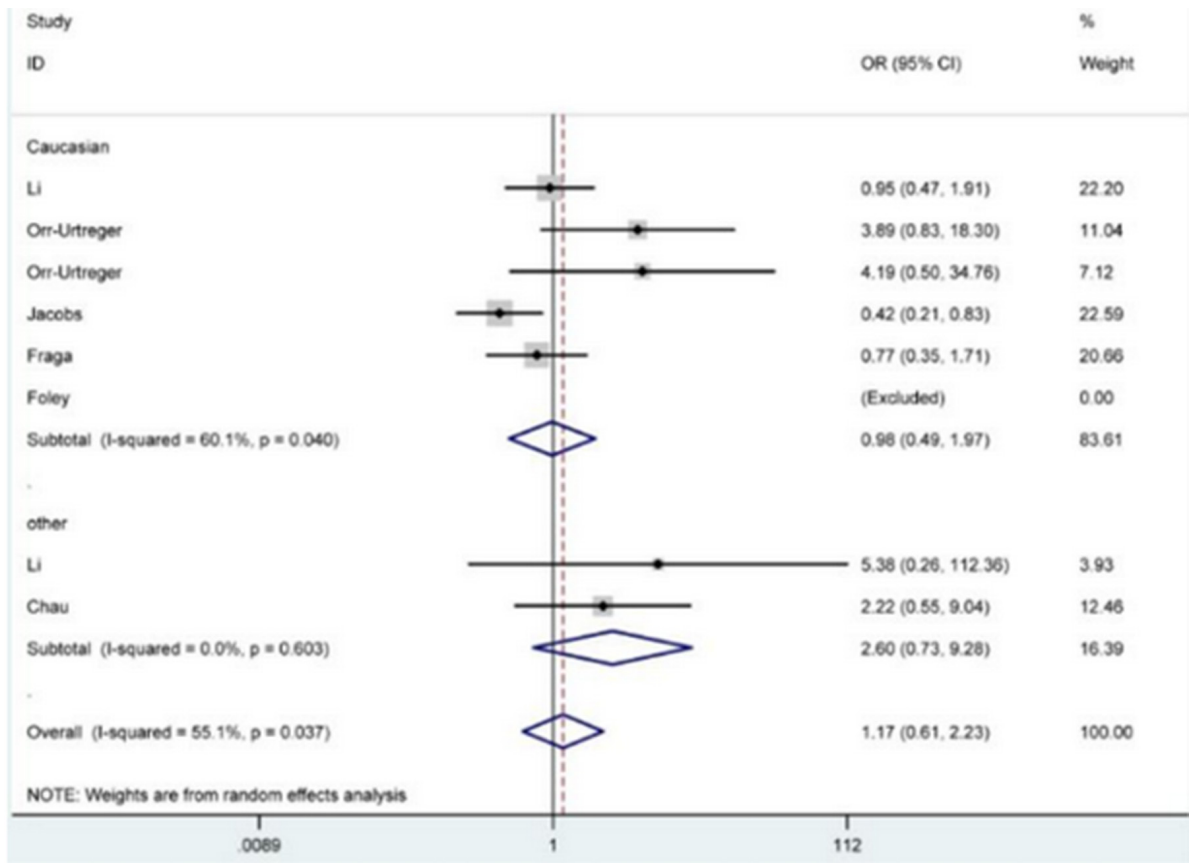

Figure 2: Forest plot for the correlation between HIF1A rs11549465 polymorphism and prostate cancer susceptibility under TT versus CC genetic model. The squares and horizontal lines correspond to the study-specific OR and 95\% CI. The area of the squares reflects the weight (inverse of the variance). The diamond represents the summary OR and $95 \% \mathrm{CI}$. 
Table 2: HIF1A rs11549465 polymorphism and risk of prostate cancer

\begin{tabular}{|c|c|c|c|c|c|c|c|c|c|c|}
\hline \multirow{3}{*}{$\begin{array}{l}\text { Genetic contrast } \\
\text { TT versus CC }\end{array}$} & \multicolumn{10}{|c|}{ Odds ratio $(95 \%$ confidence interval $) / P$ value for heterogeneity } \\
\hline & \multicolumn{2}{|l|}{ Caucasian } & \multicolumn{2}{|l|}{ Other-ethnicity } & \multicolumn{2}{|l|}{ Population-based } & \multicolumn{2}{|l|}{ Hospital-based } & \multicolumn{2}{|l|}{ Total } \\
\hline & $0.98(0.49,1.97)$ & 0.040 & $2.60(0.73,9.28)$ & 0.603 & $1.30(0.55,3.07)$ & 0.018 & $0.92(0.44,1.95)$ & 0.221 & $1.17(0.61,2.23)$ & 0.037 \\
\hline $\mathrm{TT}+\mathrm{CT}$ versus $\mathrm{CC}$ & $1.20(0.86,1.66)$ & 0.000 & $1.42(0.60,3.38)$ & 0.018 & $1.40(0.93,2.10)$ & 0.000 & $0.99(0.81,1.21)$ & 0.789 & $1.23(0.93,1.64)$ & 0.000 \\
\hline $\mathrm{TT}$ versus $\mathrm{CC}+\mathrm{CT}$ & $0.98(0.49,1.96)$ & 0.042 & $2.51(0.72,8.80)$ & 0.563 & $1.28(0.55,2.96)$ & 0.022 & $0.92(0.44,1.93)$ & 0.218 & $1.15(0.61,2.16)$ & 0.044 \\
\hline $\mathrm{CT}$ versus $\mathrm{CC}$ & $1.18(0.85,1.64)$ & 0.000 & $1.39(0.56,3.45)$ & 0.019 & $1.35(0.90,2.05)$ & 0.000 & $0.99(0.80,1.23)$ & 0.602 & $1.21(0.90,1.61)$ & 0.000 \\
\hline
\end{tabular}

funnel plots showed obvious symmetrical shapes (Figure 3 ), and results from Egger's test also supported the symmetry $(P=0.232)$, suggesting there was no significant publication bias.

\section{DISCUSSION}

Prostate cancer is a rather common disease threatening the health of older males [30]. Global statistics show that, in 2008, the standardized morbidity and mortality rates of this cancer were $82.5 / 100,000$ and $7.5 / 100,000$, respectively [31-33]. The incidence of the disease was relatively low in China previously, but in recent years we have seen an increase in its incidence and mortality [30]. At present, no effective treatment method has been introduced for advanced-stage prostate cancer. Hence, it is urgent to identify both endogenous and exogenous factors contributing to invasion, proliferation, and migration of prostate cancer. According to relevant study results, some genetic variants may predispose people to prostate cancer [34-36]. The expression of HIF1A protein has been indicated to be positively correlated with the metastatic potential and cell growth rates [3738], and its enhanced expression levels have been found in human high-grade prostate intraepithelial neoplasia (PIN) lesions as well as primary and metastatic prostate cancer [12, 39-40]. Several SNPs in the HIF1A gene have been identified, and the variant allele of the rs 11549465 polymorphism (C-to-T substitution at locus +1772 ) has been shown higher transcriptional activity under both normoxic and hypoxic conditions when compared with the wild allele [41-42]. Therefore, many scholars have associated the SNP with the occurrence risk of prostate cancer. Nevertheless, the results from different researches remain inconsistent and even contradictory.

Chau et al. investigated the contribution of HIF1A rs11549465 polymorphism to the occurrence of androgenindependent prostate cancer (AIPC), and found an apparent difference in the genotype distribution between AIPC patients and control subjects, so they concluded that the SNP might be involved in the susceptibility to AIPC [24]. Similarly, in a study by Foley et al., the heterozygous genotype $\mathrm{CT}$ was identified to be a risk factor for clinically localized prostate cancer [25]. Besides, a replicated

Begg's funnel plot with pseudo $95 \%$ confidence limits

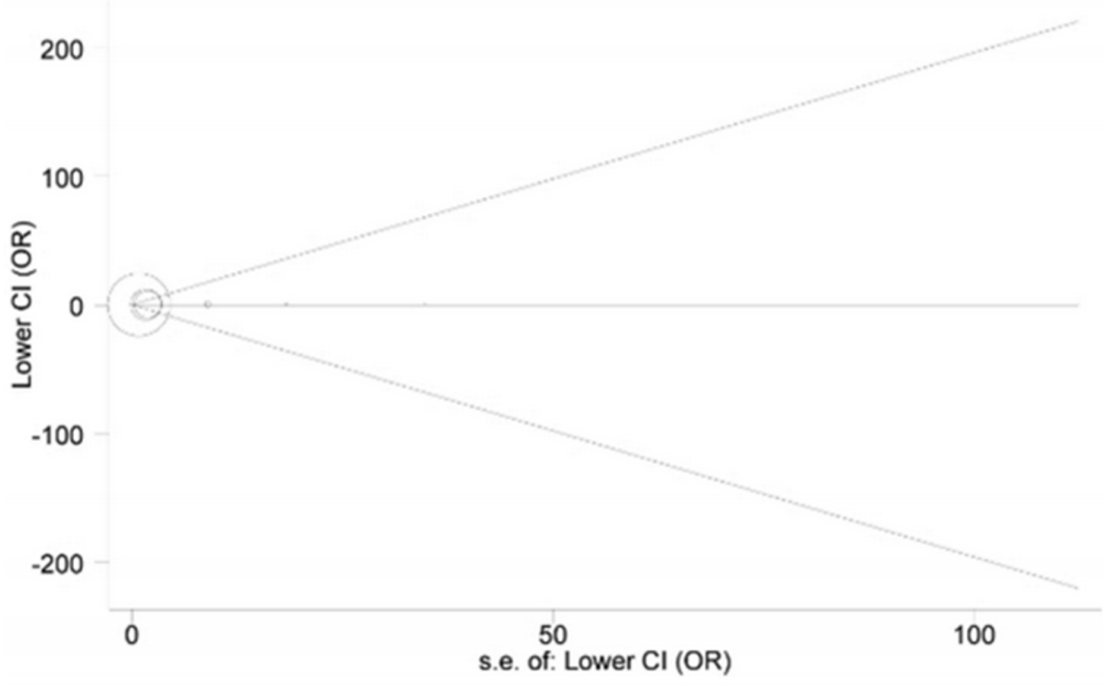

Figure 3: Begg's funnel plot of publication bias for HIF1A rs11549465 polymorphism. Each point represents a separate study for the indicated association. 
association was revealed as well among Jewish people in a research by Orr-Urtreger et al [28]. Nevertheless, Fraga et al. suggested that HIF $1 A$ rs 11549465 polymorphism was not related to the risk of prostate cancer [29]. In addition, Jacobs et al. and Li et al also insisted that the SNP had no significant impact on susceptibility to prostate cancer in their studies [14, 26].

Above controversies over the role of HIF1A rs 11549465 polymorphism in prostate cancer incidence may be due to several reasons. First of all, these studies described different types of prostate cancer. Secondly, the studies were carried out among people with different genetic backgrounds. Thirdly, different interfering environmental factors might be involved in the final results. Last but not least, studies with a small number of participants might get biased results.

In the present study, we found no statistically significant relationship between HIF1A rs11549465 polymorphism and the prostate cancer risk under any genetic comparisons, which was also true for subgroup analyses according to ethnicity and control source. Compared to the above-mentioned studies, the present meta-analysis had the advantage of larger sample size. However, some limitations in this study still should be addressed. To begin with, the influences of other relevant components such as age, gender, and smoking as well as their interactions with $H I F 1 A$ rs 11549465 polymorphism on prostate cancer occurrence were not analyzed due to the lack of original information. Second, meta-analysis is a secondary analysis and the heterogeneity is the major issue in genetic studies [43-44]. In our study, significant heterogeneity existed between the included studies, which might reflect differences in selection criteria, patients' ethnicity, control source and analysis methodologies. Moreover, insufficient data provided in included studies restricted further evaluation of potential impacts of this polymorphism on aggressive prostate cancer and response to hormonal treatment, which might play an important role in the severity of the clinical disease. Next, only studies published in English or Chinese language were incorporated into the present study, so some potentially relevant data unpublished or published in other languages might be missed, thus leading to publication bias to some extent though it was not detected. Then, the majority of included studies offered information about Caucasian populations, which might cause selective bias. Therefore, the findings from this study need to be applied with prudence.

Taken together, the present meta-analysis manifests that HIF1A rs11549465 polymorphism may not be an independent risk factor for prostate cancer. However, due to the above limitations, our conclusions should be verified by multi-center studies with larger sample sizes based on multiple ethnic groups. Importantly, more attention should be paid to the roles of polymorphisms and their genetic variants in clinical aggressiveness and therapeutic response in future work.

\section{MATERIALS AND METHODS}

This meta-analysis was reported according to the Preferred Reporting Items for Systematic Reviews and Meta-Analysis (PRISMA) statement [45] (PRISMA Checklist see Supplementary Table S1).

\section{Literature retrieval}

The electronic databases of PubMed, EMBASE and Chinese National Knowledge Infrastructure (CNKI) as well as other sources were searched for relevant reports concerning on the role of HIF $1 A$ rs 11549465 polymorphism in the occurrence of prostate cancer. The following search terms were adopted: " $H I F 1 A$ " or "HIF-1 $\alpha$ ", "prostate cancer" or "prostatic cancer", and "polymorphism" or "variant" or "mutation" or "SNP". Additionally, the references of all pertinent articles were manually checked for other relevant articles.

\section{Eligibility criteria}

Eligible studies enrolled in the meta-analysis were required to fulfill the following criteria: (1) evaluating the association between HIF1A rs11549465 polymorphism and risk of prostate cancer; (2) with a case-control design; (3) published in English or Chinese language; and (4) containing sufficient data on genotype and/or allele frequencies both in case and control groups. Studies with any one of the following characteristics were excluded: (1) with only cases; (2) comment, review, or abstract; (3) animal study; and (4) offering duplicated content.

\section{Data extraction}

The following items were extracted by two independent investigators using a specific sheet: name of the first author, publication year, country, ethnic line, control source, method for genotyping, total numbers of cases and controls, genotype and/or allele frequencies in cases and controls, and $P$ values for Hardy-Weinberg Equilibrium (HWE) in control groups. Conflicting opinions over extracted data were resolved by discussion between the two investigators so as to reach a consensus.

\section{Statistical analysis}

STATA software (version 12.0) was applied to perform all statistical calculations in this meta-analysis. $P$ $<0.05$ was considered as statistical significance. Whether genotype distribution in control group was in accordance with HWE was assessed by Chi-square test. ORs and 95\% CIs were calculated to examine the strength of correlation between HIF $1 A$ rs 11549465 polymorphism and prostate 
cancer susceptibility. The significance of pooled ORs was determined by $\mathrm{Z}$ test. Degree of heterogeneity across studies was evaluated by Chi-square-based Q test. In case of $P<0.05$, indicating significant heterogeneity, randomeffects model was applied to calculate pooled ORs; otherwise, fixed-effects model was used. The stability of final results was assessed by conducting sensitivity analysis. Begg's funnel plots and Egger's linear regression test were carried out to determine the underlying publication bias.

\section{CONFLICTS OF INTEREST}

The authors declare no conflict of interest

\section{REFERENCES}

1. Ferlay J, Soerjomataram I, Dikshit R, Eser S, Mathers C, Rebelo M, Parkin DM, Forman D, Bray F. Cancer incidence and mortality worldwide: sources, methods and major patterns in GLOBOCAN 2012. International journal of cancer. 2015; 136:E359-386.

2. Ozturk H, Karapolat I. F-fluorodeoxyglucose PET/CT for detection of disease in patients with prostate-specific antigen relapse following radical treatment of a local-stage prostate cancer. Oncology letters. 2016; 11:316-322.

3. Jemal A, Siegel R, Xu J, Ward E. Cancer statistics, 2010. CA Cancer J Clin. 2010; 60:277-300.

4. Jemal A, Siegel R, Ward E, Hao Y, Xu J, Murray T, Thun MJ. Cancer statistics, 2008. CA Cancer J Clin. 2008; 58:7196.

5. Hemminki K. Familial risk and familial survival in prostate cancer. World journal of urology. 2012; 30:143-148.

6. Zeegers MP, Jellema A, Ostrer H. Empiric risk of prostate carcinoma for relatives of patients with prostate carcinoma: a meta-analysis. Cancer. 2003; 97:1894-1903.

7. Leitzmann MF, Rohrmann S. Risk factors for the onset of prostatic cancer: age, location, and behavioral correlates. Clinical epidemiology. 2012; 4:1-11.

8. Nicholson B, Theodorescu D. Angiogenesis and prostate cancer tumor growth. Journal of cellular biochemistry. 2004; 91:125-150.

9. Hrouda D, Nicol DL, Gardiner RA. The role of angiogenesis in prostate development and the pathogenesis of prostate cancer. Urological research. 2003; 30:347-355.

10. Birbrair A, Zhang T, Wang ZM, Messi ML, Mintz A, Delbono O. Pericytes at the intersection between tissue regeneration and pathology. Clin Sci (Lond). 2015; 128:8193.

11. Birbrair A, Zhang T, Wang ZM, Messi ML, Olson JD, Mintz A, Delbono O. Type-2 pericytes participate in normal and tumoral angiogenesis. American journal of physiology Cell physiology. 2014; 307:C25-38.

12. Zhong H, De Marzo AM, Laughner E, Lim M, Hilton DA,
Zagzag D, Buechler P, Isaacs WB, Semenza GL, Simons JW. Overexpression of hypoxia-inducible factor 1alpha in common human cancers and their metastases. Cancer research. 1999; 59:5830-5835.

13. Charlesworth PJ, Harris AL. Mechanisms of disease: angiogenesis in urologic malignancies. Nature clinical practice Urology. 2006; 3:157-169.

14. Jacobs EJ, Hsing AW, Bain EB, Stevens VL, Wang Y, Chen J, Chanock SJ, Zheng SL, Xu J, Thun MJ, Calle EE, Rodriguez C. Polymorphisms in angiogenesis-related genes and prostate cancer. Cancer epidemiology, biomarkers \& prevention. 2008; 17:972-977.

15. Sfar S, Saad H, Mosbah F, Chouchane L. Synergistic effect and VEGF/HSP70-hom haplotype analysis: relationship to prostate cancer risk and clinical outcome. Human immunology. 2010; 71:377-382.

16. VanCleave TT, Moore JH, Benford ML, Brock GN, Kalbfleisch T, Baumgartner RN, Lillard JW Jr, Kittles RA, Kidd LC. Interaction among variant vascular endothelial growth factor (VEGF) and its receptor in relation to prostate cancer risk. The Prostate. 2010; 70:341-352.

17. Wang GL, Semenza GL. General involvement of hypoxiainducible factor 1 in transcriptional response to hypoxia. Proceedings of the National Academy of Sciences of the United States of America. 1993; 90:4304-4308.

18. Semenza GL. Targeting HIF-1 for cancer therapy. Nature reviews Cancer. 2003; 3:721-732.

19. Semenza GL. HIF-1, O(2), and the 3 PHDs: how animal cells signal hypoxia to the nucleus. Cell. 2001; 107:1-3.

20. Kimura H, Weisz A, Ogura T, Hitomi Y, Kurashima Y, Hashimoto K, D'Acquisto F, Makuuchi M, Esumi H. Identification of hypoxia-inducible factor 1 ancillary sequence and its function in vascular endothelial growth factor gene induction by hypoxia and nitric oxide. The Journal of biological chemistry. 2001; 276:2292-2298.

21. Brennan PA, Umar T, Smith GI, Lo CH, Tant S. Expression of nitric oxide synthase-2 in cutaneous squamous cell carcinoma of the head and neck. The British journal of oral \& maxillofacial surgery. 2002; 40:191-194.

22. Wang GL, Jiang BH, Rue EA, Semenza GL. Hypoxiainducible factor 1 is a basic-helix-loop-helix-PAS heterodimer regulated by cellular $\mathrm{O} 2$ tension. Proceedings of the National Academy of Sciences of the United States of America. 1995; 92:5510-5514.

23. Talks KL, Turley H, Gatter KC, Maxwell PH, Pugh CW, Ratcliffe PJ, Harris AL. The expression and distribution of the hypoxia-inducible factors HIF-1alpha and HIF-2alpha in normal human tissues, cancers, and tumor-associated macrophages. The American journal of pathology. 2000; 157:411-421.

24. Chau CH, Permenter MG, Steinberg SM, Retter AS, Dahut WL, Price DK, Figg WD. Polymorphism in the hypoxiainducible factor 1alpha gene may confer susceptibility to androgen-independent prostate cancer. Cancer biology \& 
therapy. 2005; 4:1222-1225.

25. Foley R, Marignol L, Thomas AZ, Cullen IM, Perry AS, Tewari P, O'Grady A, Kay E, Dunne B, Loftus B, Watson WR, Fitzpatrick JM, Woodson K, et al. The HIF1alpha C1772T polymorphism may be associated with susceptibility to clinically localised prostate cancer but not with elevated expression of hypoxic biomarkers. Cancer biology \& therapy. 2009; 8:118-124.

26. Li H, Bubley GJ, Balk SP, Gaziano JM, Pollak M, Stampfer MJ, Ma J. Hypoxia-inducible factor-1alpha (HIF-1alpha) gene polymorphisms, circulating insulin-like growth factor binding protein (IGFBP)-3 levels and prostate cancer. The Prostate. 2007; 67:1354-1361.

27. Li P, Cao Q, Shao PF, Cai HZ, Zhou H, Chen JW, Qin $\mathrm{C}$, Zhang ZD, Ju XB, Yin CJ. Genetic polymorphisms in HIF1A are associated with prostate cancer risk in a Chinese population. Asian journal of andrology. 2012; 14:864-869.

28. Orr-Urtreger A, Bar-Shira A, Matzkin H, Mabjeesh NJ. The homozygous P582S mutation in the oxygen-dependent degradation domain of HIF-1 alpha is associated with increased risk for prostate cancer. The Prostate. 2007; 67:813.

29. Fraga A, Ribeiro R, Principe P, Lobato C, Pina F, Mauricio J, Monteiro C, Sousa H, Calais da Silva F, Lopes C, Medeiros R. The HIF1A functional genetic polymorphism at locus +1772 associates with progression to metastatic prostate cancer and refractoriness to hormonal castration. Eur J Cancer. 2014; 50:359-365.

30. Zhai X, Han Q, Shan Z, Qu X, Guo L, Zhou Y. Dual specificity phosphatase 6 suppresses the growth and metastasis of prostate cancer cells. Molecular medicine reports. 2014; 10:3052-3058.

31. Ferlay J, Shin HR, Bray F, Forman D, Mathers C, Parkin DM. Estimates of worldwide burden of cancer in 2008: GLOBOCAN 2008. International journal of cancer. 2010; 127:2893-2917.

32. Znaor A, Lortet-Tieulent J, Jemal A, Bray F. International variations and trends in testicular cancer incidence and mortality. European urology. 2014; 65:1095-1106.

33. Askari F, Parizi MK, Jessri M, Rashidkhani B. Fruit and vegetable intake in relation to prostate cancer in Iranian men: a case-control study. Asian Pacific journal of cancer prevention. 2014; 15:5223-5227.

34. Xu J, Zheng SL, Isaacs SD, Wiley KE, Wiklund F, Sun J, Kader AK, Li G, Purcell LD, Kim ST, Hsu FC, Stattin P, Hugosson J, et al. Inherited genetic variant predisposes to aggressive but not indolent prostate cancer. Proceedings of the National Academy of Sciences of the United States of America. 2010; 107:2136-2140.

35. Teixeira AL, Ribeiro R, Cardoso D, Pinto D, Lobo F, Fraga A, Pina F, Calais-da-Silva F, Medeiros R. Genetic polymorphism in EGF is associated with prostate cancer aggressiveness and progression-free interval in androgen blockade-treated patients. Clinical cancer research. 2008; 14:3367-3371.
36. Teixeira AL, Ribeiro R, Morais A, Lobo F, Fraga A, Pina F, Calais-da-Silva FM, Calais-da-Silva FE, Medeiros R. Combined analysis of EGF $+61 \mathrm{G}>\mathrm{A}$ and TGFB1+869T $>\mathrm{C}$ functional polymorphisms in the time to androgen independence and prostate cancer susceptibility. The pharmacogenomics journal. 2009; 9:341-346.

37. Zhong H, Agani F, Baccala AA, Laughner E, RiosecoCamacho N, Isaacs WB, Simons JW, Semenza GL. Increased expression of hypoxia inducible factor-1alpha in rat and human prostate cancer. Cancer research. 1998; 58:5280-5284.

38. Zhong H, Chiles K, Feldser D, Laughner E, Hanrahan C, Georgescu MM, Simons JW, Semenza GL. Modulation of hypoxia-inducible factor 1alpha expression by the epidermal growth factor/phosphatidylinositol 3-kinase/ PTEN/AKT/FRAP pathway in human prostate cancer cells: implications for tumor angiogenesis and therapeutics. Cancer research. 2000; 60:1541-1545.

39. Du Z, Fujiyama C, Chen Y, Masaki Z. Expression of hypoxia-inducible factor 1alpha in human normal, benign, and malignant prostate tissue. Chinese medical journal. 2003; 116:1936-1939.

40. Zhong H, Semenza GL, Simons JW, De Marzo AM. Upregulation of hypoxia-inducible factor 1alpha is an early event in prostate carcinogenesis. Cancer detection and prevention. 2004; 28:88-93.

41. Tanimoto K, Yoshiga K, Eguchi H, Kaneyasu M, Ukon K, Kumazaki T, Oue N, Yasui W, Imai K, Nakachi K, Poellinger L, Nishiyama M. Hypoxia-inducible factor-1alpha polymorphisms associated with enhanced transactivation capacity, implying clinical significance. Carcinogenesis. 2003; 24:1779-1783.

42. Smaldone MC, Maranchie JK. Clinical implications of hypoxia inducible factor in renal cell carcinoma. Urologic oncology. 2009; 27:238-245.

43. Yan Y, Weng H, Shen ZH, Wu L, Zeng XT. Association between interleukin-4 gene $-590 \mathrm{c} / \mathrm{t},-33 \mathrm{c} / \mathrm{t}$, and 70-basepair polymorphisms and periodontitis susceptibility: a metaanalysis. J Periodontol. 2014;85:e354-362.

44. Zeng X, Zhang Y, Kwong JS, Zhang C, Li S, Sun F, Niu $\mathrm{Y}, \mathrm{Du} \mathrm{L}$. The methodological quality assessment tools for preclinical and clinical studies, systematic review and meta-analysis, and clinical practice guideline: a systematic review. J Evid Based Med. 2015;8:2-10.

45. Moher D, Liberati A, Tetzlaff J, Altman DG, Group P. Preferred reporting items for systematic reviews and metaanalyses: the PRISMA statement. BMJ. 2009; 339:b2535. 